\title{
Comparative assessment of the conditions of direct and electrochemical metallization of blind holes of multilayer printed circuit boards
}

\author{
C Radic R. Latypov, ${ }^{1}{ }^{+}$Alexandra O. Desyatova, ${ }^{1,2}$ Larisa N. Maskaeva, ${ }^{2}$ \\ Vyacheslav F. Markov, ${ }^{2}$ and Sergey V. Golybev ${ }^{1}$ \\ ${ }^{1}$ Joint Stock Company "Scientific and Production Association of automatics named after academician \\ N.A. Semikhatov”. Mamina-Sibiryaka St., 145. Yekaterinburg, 620075. Sverdlovsk Region. Russia. \\ Phone: +7 (343) 214-88-67.E-mail: lrrh@mail.ru \\ ${ }^{2}$ Physical and Colloidal Chemistry Department. Ural Federal University Named after the First \\ President of Russia B.N. Yeltsin. Mira St., 19. Yekaterinburg, 620002. Sverdlovsk Region. Russia. \\ Phone:+7 (343)375-93-18.E-mail:mln@ural.ru
}

\begin{abstract}
${ }^{*}$ Supervising author; ${ }^{+}$Corresponding author
Keywords: direct metallization of blind holes, electrochemical metallization, palladium-based systems, copper coatings, multilayer printed circuit boards.
\end{abstract}

\begin{abstract}
The metal blind holes acting as interconnectors allow significantly reduce the number of layers, increase the efficiency of trace and decrease interference between the holes and signal conductors in the high frequency printed circuit boards. In this work, a comparative assessment of the conditions of direct and electrochemical metallization blind holes with diameters: 0,$2 ; 0.25 ; 0.3 ; 0.4 ; 0.6 ; 0.8 ; 1.0 \mathrm{~mm}$ and a drilling depth of $0.5 \mathrm{~mm}$ located on experimental four-layer multilayer printed circuit boards, differing in the method of applying a conductive and copper coating was carried out. It has been established that in case nonfulfillment of mandatory conditions for the production of blind holes, in particular the aspect ratio is less than or equal to unity, incomplete metallization of the walls and especially the bottom of the holes is observed. The ways of combining the processes of direct and electrochemical metallization of holes, which provide the required thickness and quality of the copper coating at reduction of general duration of operations have been proposed based on the experimental data obtained during the work with multilayer printed boards. Also it has been established that the joint placement of blind holes with a smaller and larger diameter on one multilayer printed circuit board requires a more long direct metallization in combination with electrochemical at low values of current density. Copper films deposited on the walls of the holes and on the surface of the contact pads, regardless of the proposed way of metallization, have a highly dispersed structure. The composition of the palladium catalyst layers has been studied by energy dispersive analysis. The conductive coating on the blind hole's walls contains between 1.55 and 6.77 at.\% palladium.
\end{abstract}

\section{References}

[1] A. Akylin. Complicated structures of multilayer printed circuit boards with blind and hidden holes. Technologies in the electronics industry. 2007. No.3. P.36-37. (russian)

[2] F. Clyde. Coombs. Printed circuit boards. Handbook in 2 books. Moscow: Technoshera. 2011. P.817879. (russian)

[3] A. Medvedev. PCB Production Technology. Moscow: Technoshera. 2005. 360p. (russian)

[4] J. Lundquist, A. Medvedev, V. Saltykova. The systems of the direct platting process. Components and technologies. 2003. No.4. P.204-207. (russian)

[5] G.A. Krulik. Tin-palladium catalysts for electroless plating Platin. Met. Rev. 1982. P.58-64.

[6] Bladon, Shipley Comp. Inc. Europian. Patent № 4895739, 1990.

[7] Shadow Technology. Electrochemicals. Circuit Tree, Oct. 1999. 111p.

[8] P. Grigoriev, T. Shimchuk, T. Tsivinskaya. Analysis of the technology direct metallization of the holes of printed circuit boards. Part 2. Electronics NTB. 2019. No.1. DOI: $10.22184 / 1992-$ 4178.2019.182.1.128.136

[9] T. Tamai, M. Watanabe, S. Watase, N. Nishioka, K. Matsukawa. Direct electroless copper deposition on a photolithographic pattern of palladium-nanoparticle/acrylic-polymer hybrid. Trans. Jpn. Inst. Electron. Packag. 2011. Vol.4. No.1. P.110-113. 
COMPARATIVE ASSESSMENT OF THE CONDITIONS OF DIRECT AND ELECTROCHEMICAL...

98-104

[10] Y. Shacham-Diamand, T. Osaka, Y. Okinaka, A. Sugiyama, V. Dubin. 30 years of electroless plating for semiconductor and polymer micro-systems. Microelectron. Eng. 2015. Vol.132. P.35-45.

[11] Chemical processes for the production of printed circuit boards and environmental protection. Catalog of industrial products Ostek-Service-Technology. 2010. http://промкаталог.pф/

[12] N.V. Makushina, N.D. Sergeeva. Analysis of defects in plated holes of the printed circuit boards. Design and technology of electronic means. 2018. No.1. ISSN 2071-9809 